\title{
INTENSIVE CARE RESEARCH COORDINATORS IN AUSTRALIA AND \\ NEW ZEALAND: A CROSS-SECTIONAL SURVEY OF DEMOGRAPHICS, RESPONSIBILITIES, JOB SATISFACTION AND IMPORTANCE.
}

Investigators:

Brigit Roberts* RN, IC Cert. Research Coordinator, Department of Intensive Care, Sir Charles Gairdner Hospital, Perth, Western Australia.

Glenn M Eastwood*, RN, BN(Hons) Grad Dip (Crit Care) PhD Candidate. Austin Health, Melbourne, Victoria

Heike Raunow*, RN, Onc.Cert, PG Cert (Health Econ), MPH. Research Nurse Consultant, Peter MacCallum Cancer Centre, St. Andrews Place East Melbourne, Victoria

Belinda Howe RN, IC Cert. BApSc(Nursing). Research Fellow, ANZIC Research Centre, DEPM, Monash University, Melbourne

Claire M Rickard, RN, BN, GDN (Crit Care). Professor of Nursing, Research Centre for Clinical and Community Practice Innovation, Griffith University, Brisbane, Queensland

*ICU Research Coordinators

\section{Correspondence to}

Brigit Roberts

Department of Intensive Care

Sir Charles Gairdner Hospital

Hospital Avenue

Nedlands

Western Australia 6009

Email: Brigit.Roberts@health.wa.gov.au

Telephone: 0418955401

Keywords: ICU Research Coordinators, Responsibilities, Satisfaction, Importance 


\section{ABSTRACT}

Introduction:

The achievement of successful clinical research projects depends on multiple team members including Research Coordinators (RC), who are the link between the researcher and the trial participants. The RCs main responsibility is to ensure that all research is conducted according to the appropriate protocols, regulations and guidelines.

Aim:

Description of demographics, the role and associated responsibilities and assessment of items of importance to, and satisfaction with, various job related items.

Method:

An observational web-based cross-sectional study of RCs working in Intensive Care Units (ICU) across Australia and New Zealand.

Results:

56 participants completed the survey. 40\% had more than 6 years experience in ICU research and one third held a Masters Degree. Most respondents performed research related tasks including ethics submission, patient screening, education and data collection. Autonomy and work hours were the most satisfying job characteristics reported and aspects relating to autonomy were most important for the RCs. Inadequate remuneration was of great concern to the participants.

Conclusion:

Research Coordinators in Australia and New Zealand have many and varied roles with a significant workload. Unfortunately, the RCs do not feel their employers are adequately remunerating the demand on their time and efforts. The results indicate that RCs enjoy high levels of satisfaction with general conditions and facets of their work and its environment and they remain passionate about their role in the ICU setting.

Word count: 226 


\section{INTRODUCTION}

The achievement of successful clinical research projects depends on multiple team members. The Research Coordinator (RC) is often the link between the initiating team e.g. the sponsor and the local investigator, regulatory committees and the trial participants (e.g. patients) ${ }^{1}$. The RC's main responsibility is to ensure that all research within their area of work is conducted according to appropriate protocols, regulations and guidelines of the "International Conference on Harmonisation" and "Good Clinical Research Practice",2, The principles laid out in these documents optimise research conduct in order to comply with ethical principles, ensure participant safety and protocol adherence, and to generate valid, reliable data in a scientific manner ${ }^{4}$.

Over recent years, regulatory, ethical and protocol requirements for clinical research in Australia have escalated exponentially and become increasingly prescriptive. This is similar to experiences from Europe and North America with little formal education available to train staff in these requirements potentially making the RC's tasks overwhelming under such circumstances $^{4,5}$. Anderson identified the level of role preparedness as a problematic issue for RCs employed in gene therapy in North America. From a survey of 55 RCs she reported that mentoring by the Principal Investigator $(\mathrm{PI})$ was found to be the most efficient method of training and orientation followed by self-teaching ${ }^{6}$.

The current study builds on work undertaken in 2004 when the researchers conducted a survey of their peers aimed at examining demographics and role content as well as addressing satisfaction with and importance of a number of aspects associated with the ICU RC role within Australia and New Zealand ${ }^{7,8}$. Items of concern raised in that study were inadequate professional recognition, unsatisfactory departmental research process and a perceived lack of career advancement opportunities. Hill and MacArthur ${ }^{9}$ came to the same conclusion when they surveyed 108 research nurses working in the National Health Service facilities in the district of Edinburgh (United Kingdom) during two concurrent surveys aimed at exploring professional issues related to their positions. They reported $58 \%$ had inadequate support for professional development, and $32 \%$ believed that their continuing professional 
development needs were not met. In recent years, discussion regarding the qualifications and education opportunities for RCs has increased and more formalised education opportunities are being offered for $\mathrm{RCs}^{10}$. These initiatives typically target coordinators from particular clinical specialities. Additionally, some professional research organisations offer annual certification for research professionals arguing that trial sponsors, especially in the international field, look favourably on these qualifications ${ }^{11}$.

Poor financial remuneration was another major concern in the 2004 survey. Many RCs were employed on short to medium term contracts and ongoing tenure depended on income from pharmaceutically sponsored trials. This financial uncertainty was unsettling and had the potential to become a major stressor for $\mathrm{RCs}^{7,9}$. The latest major development for Australian and New Zealand RCs and their recognition has come from a policy document from the Joint Faculty of Intensive Care Medicine stating that one full-time RC position should be a minimum requirement for Level $3^{*}$ ICUs, and a part-time position for smaller units. It is expected that this document will be influential in negotiations between ICUs and their institutions, and assist to secure recurrent institutional funding for RC positions ${ }^{12}$.

Footnote* A level 3 adult ICU must be a separate and self-contained facility in the hospital capable of providing complex, multi-system life support for an indefinite period. It must be a tertiary referral centre for intensive care patients and have extensive back up laboratory and clinical service facilities to support this tertiary referral role ${ }^{13}$.

In this paper we report a demographic and role-content mapping of Australian and New Zealand RCs employed in ICU and describe measurement of satisfaction and importance with specific job-items. We compare this current study to a similar one conducted in 2004 which described inadequate professional recognition and employment conditions for this group, to see if improvements had been made over the 5 year period as the positions became more established within the intensive care specialty.

\section{METHODS}

\section{Development of the questionnaire}


This research followed an earlier study of the RC role, and used an anonymous, structured, multi-choice questionnaire to survey RCs employed in Australian and New Zealand ICUs ${ }^{8}$ We chose a cross-sectional study design so as to measure different variables at the same timepoint and provide a picture of the phenomenon in 2009. As the earlier study was performed anonymously, and personnel would have changed over the 5 year period, a paired cohort study was not possible.

The questionnaire consisted of three parts. Part 1 contained 30 questions from the RickardRoberts Research Coordinator Survey ${ }^{7,8}$ with minor adaptations to clarify word structure. This part captured demography of participants, as well as their role and responsibilities from preselected items using a check box list.

Part 2 of the questionnaire was the previously validated 31-item McCloskey/Mueller Satisfaction Scale (MMSS), modified to 28 -items ${ }^{14}$. Three questions were removed from the original MMSS. Two of these questions "Opportunities to undertake own research" and "Write and publish own journal articles" we explored in more details under heading of Professional Development (this data will be reported separately) and one question "Satisfaction/Importance of working with ICU research staff" was already covered by other questions "Satisfaction/Importance of working with ICU medical and nursing staff". Part 3 contained the 31-item McCloskey/Mueller Importance Scale (MMSS-IS), modified to 28 items as above for the MMSS ${ }^{14}$.

These two scales ask the respondents for a score of level of satisfaction and importance with a pre-set list of items. The items in the scales are identical, however in Part 2 the questions ask about level of satisfaction on a score of $1=$ not satisfied to $10=$ very satisfied. In Part 3 the questions ask about level of importance to the respondent on a score of $1=$ not important to $10=$ very important. A comparison can then be calculated between how satisfied the respondent is with any particular item and simultaneously how important this item is to him/her. For example, a respondent may have great satisfaction with an item such as level of responsibility, and at the same time, the item is highly important to the respondent, thus there is a neutral association. However, if the respondent scores an item low on the satisfaction scale but it is very important to the respondent then a negative association will ensue. 
Similarly, high level of satisfaction with an item, but the item is not important (low score) will also result in a positive association.

Data collected from the questionnaire were analysed using descriptive statistical procedures to calculate mean and percentages. All quantitative analyses were performed using Microsoft Excel (2003) software package.

\section{Target population, recruitment and administration of the questionnaire}

The target population for the survey consisted of RCs working in Australian and New Zealand ICUs. RCs were identified using the ANZICS - Intensive Care Research Coordinators Interest Group (IRCIG) database. Prior to posting the survey, the authors obtained permission from the IRCIG Executive Committee to distribute the survey via the closed e-mail list. Participation was voluntary, anonymous and took approximately 30 minutes to complete. Responses were recorded during a 10-week period from July 2009 to October 2009. Two reminder emails were sent at 4 weeks and 6 weeks time points.

\section{Ethical considerations}

Prospective approval from the Institutional Human Research Ethics Committee at Griffith University was obtained for the survey to be conducted. An explanatory information letter was attached to the survey and clearly stated that participation was voluntary and anonymous. Responding to the survey implied participant consent. The emails contained a hyperlink to the website for the survey to be completed on-line. The computer server delivered the deidentified completed surveys electronically over the Internet to the researchers. Internet protocol (IP) addresses were not collected.

\section{RESULTS}

\section{$\underline{\text { Sample }}$}

Invitations to participate in the study were emailed to $104 \mathrm{RCs}$ from Australia and New Zealand subscribing to the IRCIG mailing list. Full responses were received from 56 RCs (54\%). Respondents were 91\% female, with the majority (77\%) aged between 31 and 50 
years. There was no uniformity in job title however, a slight majority (52\%) used the title of Research Coordinator, with the remainder using various combinations of the words clinical, research, coordinator, manager, and nurse.

Nearly all RCs (84\%) worked in metropolitan, university-affiliated, public hospitals caring for medical and surgical adult intensive care patients. Over two-thirds of RCs (68\%) worked in units employing more than one RC to undertake clinical research with $36 \%$ of units employing between 2 and 4 Full Time Equivalent (FTE).

\section{Education and Work Experience}

RCs' chronological experience in ICU research was equally distributed between 3 time periods: 1-3 years, 4-6 years and $>10 y e a r s$ (30\% in each group), and most worked either fulltime (45\%) or 3-4 days per week (38\%). Many RCs (36\%) had a second job, and $15(27 \%)$ worked 11-20 hours per week in their second job, with a single respondent working 1 to 10 hours per week in a third job.

All respondents had qualifications in nursing, and the highest tertiary qualifications completed were at Graduate Certificate (21\%), Graduate Diploma (21\%) or Masters (21\%) level, with $18 \%$ currently studying for a Masters (coursework), and $5 \%$ for a $\mathrm{PhD}$ or other Doctorate. Table 1 further describes the sample. The asterix refers to a noted discrepancy between "Experience in Critical Care Clinical Research" and "Overall Experience in Clinical Research". In total, $38 \%$ reported that their employer provided them with specific research training days to develop research knowledge and skills (this excludes pharmaceutical sponsored or other multi-centre trial specific "start-up" meetings). Similarly 38\% were provided with support (either through their industrial award conditions, or on individual request to their manager) to undertake studies for formal research specific qualifications such as clinical trials management or Masters by Research. Specific training days in ethics and /or management of ethical issues was provided by $18 \%$ of employers.

\section{$\underline{\text { Role Content and Structure }}$}

The majority of RCs managed audits and data registries (93\%), pharmaceutical industry sponsored trials (88\%) and multi-centred regional trials (84\%). Many also partook in 
departmental medical initiated trials (79\%) and departmental nursing initiated studies (52\%). Just under a third of RCs (30\%) initiated their own research. Most RCs were involved in several concurrent projects with $67 \%$ having had an active role in 8 or more projects within the preceding 12 months. Table 2 describes the most common roles and responsibilities of the RCs, with the top 10 items performed by more than $81 \%$ of RCs. Data-base design, statistical analysis, conference presentations, writing journal articles, membership of institutional human research ethics committees, and laboratory-based research were performed by less than half of the cohort. These tasks tended to be performed more frequently by RCs with $>10$ years experience in critical care research, except participation in laboratory research, where there was no association with length of experience as RC.

\section{$\underline{\text { Satisfaction and Importance Scores }}$}

Table 3 explains how satisfied the RCs were with job-items relating to their current work conditions, as well as the actual importance of these items to their individual situation. Whereas most items rated mean satisfaction scores greater than 7 , in relation to their importance to the RCs, most items from the scale had a mean rating equal to or above 8 . Any discrepancies between mean satisfaction with an item and their actual importance to the group are outlined in the last column. The results demonstrated sufficient correspondence indicating that RCs were satisfied with their conditions and that those conditions were also important to the RCs. Over half of the 28 items $(n=18)$ had an association of 0 or plus/minus 1.99, 8 items had a negative association of -2 to -2.99 points on the mean score and 2 items, "Compensation for weekend work" and "Encouragement/feedback about your work" scored >-3. Five items had positive scores, demonstrating higher satisfaction with the items, but less importance to the respondents. More than $95 \%$ of survey participants responded to most of the MMSS \& MMSS-IS questions however, only between 33\% and $48 \%$ answered the items related to child care facilities and maternity/paternity leave.

\section{DISCUSSION}

Consistent with our 2004 study, the majority of RCs are females, aged between 30 and 50 with a background in nursing. Many responders had long-term experience in ICU research 
with $39 \%$ having worked in the RC role for more than 6 years. This was a significant increase from our previous survey in 2004 , where only $12 \%$ had been working in ICU research for more than 6 years. This is likely an indication that the ANZICS Clinical Trials Group (CTG) has now been active for over 10 years with general increase in ICU focused activity and complexity. In addition, it appears to reflect broad job satisfaction as many incumbents have chosen to remain in the positions in the longer term.

Nearly one quarter of RCs were studying towards a Masters or PhD/doctoral degree, which is similar to our previous study. However in 2004 only $8 \%$ had completed their Masters, with the more recent data showing $32 \%$ qualified at this level. Both surveys reflect the tendency of RCs to seek higher educational achievements. Curtis and Donoghue ${ }^{15}$ found that trauma nurse coordinators (a role similar to RCs with responsibilities including data collection and data base maintenance) in Australia and New Zealand also had both long experience (median 11 years) within their field, and a high proportion (78\%) possessed graduate qualifications, and $42 \%$ at Masters or higher level.

It is vital for high quality clinical research, and in light of the increasingly complex ethical and regulatory requirements, that RCs are provided with the opportunity to undertake relevant further education. Only slightly more than one-third of the RCs in our study were offered and supported in these activities. A formal mentorship programme within Australian and New Zealand ICU RCs is still in its infancy. It would be welcome to see this programme adding a training component in the future as RCs often work in isolation with little opportunity for collaboration and interaction amongst peers. Only 18\% reported receiving specific training in ethical issues. These figures are somewhat lower than Anderson reports, where $55 \%$ were provided with funding for further training and on-going education and about half had undertaken approved on-line tutorial in ethical matters ${ }^{6}$. However, it is uncertain if the latter figure includes training at sponsored so-called "start-up" meetings, where ethical training forms part of the mandatory education and is often left to a short presentation. We excluded those as training days since they are sponsored by a pharmaceutical company or research organisation and training is specific for a trial product. There are likely to be differences to 
funding and support for education in award and employment structures between North America and Australia and New Zealand.

The type of research appears to have shifted dramatically in the last five years with more RCs being involved in audits, up from $59 \%$ in 2004 to the current $93 \%$. This increase may suggest that the ANZICS-CTG is now conducting large multi-centred studies in addition to locally based clinical trials. It may also suggest increased collaboration with intensive care societies on a global scale giving access for units to participate in international studies. This growth in workload is absorbed through a $34 \%$ increase in numbers of RCs being employed throughout the region. The remaining categories such as pharmaceutical industry sponsored, multicentred regional, departmental medical and nursing trials remain static and may reflect a lack of funds available to undertake larger scale trials.

Few jobs in the health sector cover such an array of duties from resource and budgetary assessment, to patient advocacy and teaching, clinical assessments, laboratory processing, pharmaceutical understanding of trial drugs and their potential inter-actions and adverse effects and matters relating to regulatory authorities. Although some may argue that the Principal Investigator is ultimately responsible for the conduct of a trial, $71 \%$ of RCs indicated that they made decisions on his/her behalf.

In comparison to the 2004 results, two roles are now being carried out by significantly more RCs. One is managing trial budgets (a rise from $47 \%$ to $86 \%$ ), which may reflect a shift from a single per patient payment for participation in clinical trials, to the now common model of remuneration based on individual protocol items. Budgeting can be a substantial burden for RCs, who usually lack formal finance or business training, but are now expected to negotiate costing for consumables, procedures, trial administration time and final payments. The other duty to have increased from the survey in 2004 is active participation on Human Research Ethics Committees, a rise from $18 \%$ to current $21 \%$ sitting on committees and $70 \%$ actively participating in HREC meetings. One could postulate it signals recognition and maturity of the position outside the critical care domain. Laboratory research saw a drop from $22 \%$ of respondents in 2004 to only $9 \%(n=5)$ in the current study which could indicate that fewer 
respondents are currently studying hence, no requirement for undertaking such research. The types of laboratory research are not differentiated between bench-work and animal research and no specific qualification dominated the participants in this task.

\section{Satisfaction and Importance}

Overall evaluation of the ranked items in the MMSS and MMSS-IS demonstrate that the level of satisfaction in relation to importance has remained static from our survey conducted in 2004 , which is interesting taking into account the influx of RCs to ICU has risen by $34 \%$. The level of satisfaction remains at the top end of the scale, and similarly, most items are of great importance.

The most satisfying aspects of the RC role were work conditions (e.g. work hours and autonomy) and personal interaction, and the least satisfying items related to remuneration and opportunities for promotion. Other studies assessing similar concepts have found comparable results and have concluded that equitable remuneration, control over the work environment and a review of the career pathway may assist in minimising work-related stress $^{16,17,18,}$

Access to a childcare facility ranked the least satisfactory of all items, with a mean score of 4.05. Less than half the respondents (34-48\%) ranked the satisfaction and importance items regarding childcare and parental leave, presumably representing the number of currently affected parents in this cohort. Considering nearly half the respondents (46\%) were aged below 41 years, access to childcare facilities and parental leave are certainly items that need to be addressed in current and future planning.

Converging the results from the two scales, MMSS and MMSS-IS gives an important insight to areas in need of attention by employers in order to create balance between satisfaction and importance, and gives the prospect to address priorities for improving job satisfaction and thereby provide a means to increase staff retention. Employers do not seem to have taken heed of the results from the survey in 2004, where lack of compensation for working weekends, remuneration and lack of career advancement opportunity scored the largest 
discrepancies. Whether compensation for weekends involves a monetary component or timein-lieu is not revealed in this study and would most likely best be negotiated by the individual units and RCs. There is also budgetary constraint in the current health economic climate, underestimating the actual cost of RCs and lack of replacement or relief for the RC. Another influencing factor as reported in the literature relate to many RCs being employed on short to middle-term contracts and their ongoing tenure is linked to income from pharmaceutical sponsored clinical trials and grants ${ }^{9}$. The importance of having flexibility to work part time continues to be outweighed by the level of satisfaction. Findings from our study identified that $>50 \%$ of RCs work part-time, and that many have a second job outside ICU research. It may be that RCs wish to continue some clinical work, or that they need this as a 'top up' of their income to full-time but there was a lack of opportunity for full-time RC employment or a lack of funding for a full-time RC position.

Anecdotally, there has been an increase in permanent tenures across Australia and New Zealand in recent times. This may be the result of a policy document from the Joint Faculty of Intensive Care Medicine regarding the employment of RCs as one of their requirements, which is certain to support a business case. Alternatively, hospital management may be intrinsically recognising the RC position and be supporting more ICUs to create a permanent position if they see the value that research adds to the hospital profile.

The RCs are educators, patient advocates, and care-givers amongst other attributes and they are fiercely proud of managing a study with attention to the many minute details required in order to manage a safe and successful study ${ }^{19}$. However, it is often difficult for colleagues within the unit to fully appreciate the work involved in completing a study, as many see trial participation as an added burden in caring for the patient. There may also be some resentment from clinical staff as the RC very often enjoys a high level of autonomy to which few other healthcare workers have access. From the current study, it transpires that despite long hours and frequently being isolated from peers, the RC desires more respect and recognition from colleagues and at times also from their immediate supervisor. Recognition may come in the form of enabling the RC to provide input into decision-making and application of research, ensuring the RC is kept informed about progress and provided with 
feedback from the work he/she performs, and inclusion of the RC in the authorship process for submitted articles. However, in regard to social contact rather than professional collaboration, the satisfaction exceeded the importance. A strong social network may help alleviate but not eliminate some of the stressors induced by lack of recognition.

Ultimately, it is very encouraging and a positive sign to note that all items scored above average, 6 on a scale of 1 to 10 for importance, and 23 out of 28 items on the satisfaction scale ranked above 6 , clearly indicating a high level of satisfaction with the general work conditions and environment.

\section{Limitations}

A limitation of the study is the low response rate of $54 \%$, which was well below the $71 \%$ response rate of the 2004 survey. The lower than expected response rate may be explained by the survey being conducted at the height of the $\mathrm{H} 1 \mathrm{~N} 1$ pandemic in this region, resulting in a heavy workload throughout the ICU community. The use of a cross-sectional design limits the comparison of the results from the 2004 and 2009 surveys, since changes in the individuals filling the RC positions may have been responsible for some of the changes over time, rather than environmental professional factors. Lastly, it may not be possible to translate data from this select group of health care workers from a limited geographical region (Australia and New Zealand) to other groups. However, it is evident from the literature, that our results seem much aligned with other reported observations and surveys of RCs from different areas of health ${ }^{1,19,20}$. This implies that it is not just the health care speciality, but also the actual position as RC, which unites these professionals.

\section{CONCLUSION}

Research coordinators in Australia and New Zealand are likely to have extensive research and educational experience. Although areas of commonality exist, their roles are many and varied and they typically manage multiple concurrent projects. Subsequently the workload is significant and unfortunately, the RCs do not feel their employers are adequately remunerating the demand on their time and efforts. Opportunities for ongoing educational development and a clear career path are problematic. 
Nevertheless, nearly $40 \%$ of RCs have been in their position for more than 7 years, and our results indicate that RCs enjoy high levels of satisfaction with general conditions and aspects of their work and its environment and they remain passionate about their role in the ICU setting.

\section{ACKNOWLEDGEMENT}

The authors wish to thank all those RCs who completed the survey, without your support, we could not have completed this project. 


\section{REFERENCE LIST}

1. PA Jellen, FL Brogan, AM Kuzma, C Meldrum, YM Meli \& CL Grabianowski. NETT Coordinators. Researchers, caregivers or both? Proc Am Thorac Soc 2008;5:412-5.

2. www.ich.org Accessed on $2^{\text {nd }}$ April 2010.

3. http://www.nhmrc.gov.au Accessed on $4^{\text {th }}$ November 2010. National Health and Medical Research Council, Australian Research Council, Australian Vice-Chancellor's Committee. "National Statement on Ethical Conduct in Human Research." Australian Government 2007,

4. C Mori, N Mullen, EE Hill. Describing the role of the clinical research nurse. Research Practitioner 2007;8(6):220-8.

5. P Chester, ED Kennedy, S Hynd, DR Matthews. Clinical research networks in diabetes: the evolving role of the research nurse. Eur Diab Nurs 2007;4(1):10-13.

6. G Anderson. Ethical preparedness and performance of gene therapy study coordinators. Nursing Ethics 2008;15(2):208-221.

7. CM Rickard, BL Roberts, JW Foote, MR McGrail. Intensive Care Research Coordinators: who are they and what do they do? Results of a bi-national survey. Dimens Crit Care Nurs 2006;25(5):234-242.

8. CM Rickard, BL Roberts, JW Foote, MR McGrail. Job satisfaction and importance for intensive care unit research coordinators: Result from binational survey. J Clin Nurs 2007;16:1640-50. 
9. G Hill, J MacArthur. Professional issues associated with the role of the research nurse. Nursing Standard, 2006;20(39):41-7.

10. Proceedings CRX 07\&08 Conference Careers Stream Melbourne 07, Research Education and Ethics Stream, Brisbane 08.

11. M Chiam, A Giddy, R Lichter, J Morrison. Conducting Clinical Trials in Australia. Monitor ARCP Journal 2007;21(3):51-55; Clinical Research Special Edition; The University of Melbourne Consulting and Customs Program Bulletin May 2008.

12. www.cicm.org.au/policydocs.php 2010 IC3 Section 3.5 Accessed $15^{\text {th }}$ April 2010

13. www.dhs.vic.gov.au/ahs/archive/prs2/parta/prs03.htm Accessed on 15th April 2010

14. CW Mueller, JC McCloskey. Nurses' job satisfaction: A proposed measure. Nursing Research 1990;39:113-7.

15. K Curtis, J Donoghue. The trauma nurse coordinator in Australia and New Zealand: A progress survey of demographics, role function, and resources. J Traum Nurs 2008;15(2):34-42.

16. MT Kluger, J Bryant. Job satisfaction, stress and burnout in anaesthetic technicians in New Zealand. Anaesth Int Care 2008;36:214-21.

17. M Price. Job satisfaction of registered nurses working in an acute hospital. $\mathrm{Br} J$ Nurs 2002;11(4):275-280

18. BL Roberts, CM Rickard, JW Foote, MR McGrail. The best and worst aspects of the ICU research coordinator role. Nurs Crit Care 2006;11(3):128-135. 
19. S Fowler, K Stack. Research and the clinical trials coordinator. J Neurosci Nurs 2007;39:120-123.

20. F Rico-Villademoros, T Hernando, JL Sanz, A Lopez-Alonso, O Salamanca, C Camps, R Rosell. The role of the clinical research coordinator-data manager-in oncology clinical trials. BMC Medical Research Methodology 2004;4:3-12 
TABLE 1. Demographics and educational characteristics of RCs

\begin{tabular}{|c|c|c|c|}
\hline Characteristics & & Number (N) & $\%$ \\
\hline \multicolumn{4}{|l|}{ Gender } \\
\hline & Female & 51 & 91 \\
\hline & Male & 5 & 9 \\
\hline \multicolumn{4}{|l|}{ Age (years) } \\
\hline & $21-30$ & 5 & 9 \\
\hline & $31-40$ & 21 & 38 \\
\hline & $41-50$ & 22 & 39 \\
\hline & $51-60$ & 7 & 13 \\
\hline & $>60$ & 1 & 2 \\
\hline \multicolumn{4}{|l|}{$\begin{array}{l}\text { Experience in critical } \\
\text { care research } \\
\text { (years) }\end{array}$} \\
\hline & $<1$ & 2 & 4 \\
\hline & $1-3$ & 17 & 30 \\
\hline & $4-6$ & 15 & 27 \\
\hline & $7-10$ & 7 & 13 \\
\hline & $>10$ & 15 & 27 \\
\hline \multicolumn{4}{|l|}{$\begin{array}{l}\text { Overall experience } \\
\text { in clinical research } \\
\text { (years) }(\mathrm{N}=52)\end{array}$} \\
\hline & $<1$ & $9^{*}$ & $17^{\star}$ \\
\hline & $1-3$ & 11 & 21 \\
\hline & $4-6$ & 12 & 23 \\
\hline & $7-10$ & 8 & 15 \\
\hline & $>10$ & 12 & 23 \\
\hline \multicolumn{4}{|l|}{ Employment $(\mathrm{N}=55)$} \\
\hline & Full time & 25 & 45 \\
\hline & 1-2 days per week & 9 & 16 \\
\hline & 3-4 days per week & 21 & 38 \\
\hline \multicolumn{4}{|l|}{$\begin{array}{l}\text { Highest completed } \\
\text { qualification }\end{array}$} \\
\hline & $\begin{array}{l}\text { Hospital general nursing } \\
\text { certificate }\end{array}$ & 1 & 2 \\
\hline & $\begin{array}{l}\text { Hospital speciality } \\
\text { nursing certificate }\end{array}$ & 4 & 7 \\
\hline & Diploma & 2 & 4 \\
\hline & Bachelor degree & 6 & 11 \\
\hline & Honours degree & 1 & 2 \\
\hline & Graduate certificate & 12 & 21 \\
\hline & Graduate diploma & 12 & 21 \\
\hline & Masters (coursework) & 12 & 21 \\
\hline & Masters (research) & 6 & 11 \\
\hline \multirow[t]{6}{*}{$\begin{array}{l}\text { Studying towards } \\
\text { tertiary award }(\mathrm{n}=16 \\
(29 \%))\end{array}$} & & & \\
\hline & Honours & 1 & 2 \\
\hline & Masters (coursework) & 10 & 18 \\
\hline & Masters (research) & 1 & 2 \\
\hline & PhD / Doctorate & 3 & 5 \\
\hline & Other (not specified) & 1 & 2 \\
\hline
\end{tabular}

* Noted discrepancy between Experience in Critical Care Research and Overall Experience in Clinical Research 
TABLE 2 Responsibilities of ICU Research Coordinators

\begin{tabular}{|l|c|c|c|}
\hline Item & $\begin{array}{l}\text { Affirmative } \\
\text { score } \\
\text { (N=56) }\end{array}$ & $\%$ & Ranking \\
\hline Ethics submissions & 56 & 100 & 1 \\
\hline Teach protocol and study specific procedures to ICU staff & 55 & 98 & 2 \\
\hline Patient screening for trial eligibility & 54 & 96 & 3 \\
\hline Patient assessment & 54 & 96 & 3 \\
\hline Provide education and support to patient and family & 54 & 96 & 3 \\
\hline Data collection/entry/transcription & 54 & 96 & 3 \\
\hline Attend to regulatory requirements and ethical matters & 53 & 95 & 4 \\
\hline Review protocol for feasibility & 51 & 91 & 5 \\
\hline $\begin{array}{l}\text { Collect and process biological specimens for local } \\
\text { processing }\end{array}$ & 50 & 89 & 6 \\
\hline $\begin{array}{l}\text { Collect and process biological specimens for international } \\
\text { processing }\end{array}$ & 49 & 88 & 7 \\
\hline Manage study budgets & 48 & 86 & 8 \\
\hline Teach research topics to ICU staff & 47 & 84 & 9 \\
\hline Prepare study budgets & 46 & 82 & 10 \\
\hline Obtain consent & 45 & 80 & 11 \\
\hline Design data collection tools & 43 & 77 & 12 \\
\hline Protocol development & 41 & 73 & 13 \\
\hline Negotiate with pharmaceutical company representative & 41 & 73 & 13 \\
\hline Make decisions on behalf of the Principal Investigator & 40 & 71 & 14 \\
\hline Active participant in unit/hospital HREC* meetings & 39 & 70 & 15 \\
\hline Literature searches & 37 & 66 & 16 \\
\hline Collate research results & 35 & 63 & 17 \\
\hline Prepare grant submissions & 30 & 54 & 18 \\
\hline Design databases & 27 & 48 & 19 \\
\hline Perform statistical analysis of study data & 16 & 29 & 20 \\
\hline Write articles for publication & 16 & 29 & 20 \\
\hline Present study results at conferences/congresses & 14 & 25 & 21 \\
\hline Member of HREC* & 5 & 21 & 22 \\
\hline Perform laboratory research & 9 & 23 \\
\hline Numan Research En & & \\
\hline
\end{tabular}

*Human Research Ethics Committee 
TABLE 3. The level of satisfaction and importance on set items describing the ICU research work environment and the discrepancy between satisfaction with and importance of any given item

\begin{tabular}{|c|c|c|c|c|c|}
\hline Item & $\begin{array}{l}\text { Satisfaction } \\
\text { (N) }\end{array}$ & Satis mean & $\begin{array}{l}\text { Importance } \\
\text { (N) }\end{array}$ & Import mean & $\begin{array}{l}\text { Diff }(S-I) \\
\text { mean }\end{array}$ \\
\hline $\begin{array}{l}\text { Compensation for working } \\
\text { weekends }\end{array}$ & 50 & 5.24 & 53 & 8.85 & -3.61 \\
\hline $\begin{array}{l}\text { Encouragement/feedback about } \\
\text { your work }\end{array}$ & 56 & 5.89 & 55 & 8.96 & -3.07 \\
\hline Remuneration package & 55 & 4.98 & 55 & 7.91 & -2.93 \\
\hline Salary & 55 & 5.85 & 56 & 8.52 & -2.67 \\
\hline $\begin{array}{l}\text { Career development } \\
\text { opportunities }\end{array}$ & 56 & 5.95 & 53 & 8.60 & -2.65 \\
\hline $\begin{array}{l}\text { Overall structure \& application of } \\
\text { research in local ICU }\end{array}$ & 55 & 6.65 & 55 & 9.09 & -2.44 \\
\hline $\begin{array}{l}\text { Control over work content \& } \\
\text { workload }\end{array}$ & 56 & 6.84 & 55 & 9.13 & -2.29 \\
\hline Input into decision-making & 55 & 7.24 & 55 & 9.35 & -2.11 \\
\hline Childcare facility ${ }^{\star}$ & 19 & 4.05 & 25 & 6.12 & -2.07 \\
\hline $\begin{array}{l}\text { Respect/recognition from within } \\
\text { ICU (medical staff) }\end{array}$ & 55 & 6.69 & 55 & 8.73 & -2.04 \\
\hline $\begin{array}{l}\text { Respect/recognition from within } \\
\text { ICU (nursing staff) }\end{array}$ & 55 & 6.67 & 55 & 8.62 & -1.95 \\
\hline Hours worked per week & 55 & 6.67 & 55 & 8.6 & -1.93 \\
\hline Control over work environment & 55 & 7.38 & 55 & 9.25 & -1.87 \\
\hline Leave entitlements & 55 & 7.07 & 56 & 8.89 & -1.82 \\
\hline Opportunity to work part-time & 49 & 7.37 & 50 & 8.66 & -1.29 \\
\hline Level of responsibility & 55 & 7.96 & 54 & 8.93 & -0.97 \\
\hline Immediate supervisor & 52 & 7.75 & 55 & 8.69 & -0.94 \\
\hline $\begin{array}{l}\text { Flexibility for weekends off with } \\
\text { being on-call }\end{array}$ & 46 & 7.74 & 51 & 8.63 & -0.89 \\
\hline Working with ICU medical staff & 55 & 7.54 & 55 & 8.38 & -0.84 \\
\hline $\begin{array}{l}\text { Opportunities to work non-shift } \\
\text { work (business hours) }\end{array}$ & 53 & 8.36 & 55 & 8.96 & $\begin{array}{c}-0.6 \\
\end{array}$ \\
\hline Working with ICU nursing staff & 53 & 8.25 & 54 & 8.46 & -.021 \\
\hline $\begin{array}{l}\text { Opportunity to interact with } \\
\text { university } \\
\text { departments/academics }\end{array}$ & 49 & 6.61 & 54 & 6.82 & -0.21 \\
\hline $\begin{array}{l}\text { Number of weekends off per } \\
\text { month }\end{array}$ & 54 & 8.28 & 56 & 8.36 & -0.08 \\
\hline
\end{tabular}




\begin{tabular}{|l|l|l|l|l|l|}
\hline $\begin{array}{l}\text { Social contact with colleagues at } \\
\text { work }\end{array}$ & 50 & 7.92 & 55 & 7.73 & +0.19 \\
\hline $\begin{array}{l}\text { Opportunity to be included on } \\
\text { ICU/hospital committees }\end{array}$ & 49 & 6.33 & 55 & 6.13 & +0.2 \\
\hline Maternity/paternity leave & 25 & 7.8 & 27 & 7.52 & +0.28 \\
\hline $\begin{array}{l}\text { Opportunity for inter-disciplinary } \\
\text { contact }\end{array}$ & 54 & 8.11 & 55 & 7.38 & +0.73 \\
\hline $\begin{array}{l}\text { Social contact with colleagues } \\
\text { outside work }\end{array}$ & 51 & 8.12 & 54 & 6.5 & +1.62 \\
\hline
\end{tabular}

10 point scale, with $1=$ least sat $/$ imp and $10=$ most sat $/$ imp 